\title{
The process of life goals' pursuit and the satisfaction of basic psychological needs: the predictive role of personality factors
}

\author{
Daniela Ionescu $^{1}$ \\ ${ }^{1}$ Department of Psychology, "Alexandru Ioan Cuza" University of Iaşi, Romania
}

Received 28.02.2017; Received revised 10.06.2017; Accepted 18.06.2017

Available online 30.06 .2017

\begin{abstract}
The aim of the study is to explore the role that personality variables have on the progress in achieving goals and satisfying basic psychological needs (the need for autonomy, competence and relatedness). The participants (231 subjects of the regular population) have been asked to fill in the evaluation forms suggested in order to measure the variables of the present research. In order to analyze the data we have used correlation and linear regression analyses. Neuroticism, optimism, motivational persistency, self-authenticity and self-concordance in goal establishment are significant predictors in the progress made towards the intended goal and the satisfaction of an individual's basic psychological needs. The successful achievement of the life goals engenders firstly the choice of authentic goals, which are concordant with the individual self that the individual shall follow perseveringly and optimistically, making constant efforts towards achieving them. Moreover, an optimistic state of mind and the absence of negative emotional states support the process of goal pursuit.
\end{abstract}

Keywords: Life goals, Basic psychological needs, Personality.

Address of correspondence: Daniela Ionescu, Department of Psychology, Alexandru Ioan Cuza University of Iasi, Toma Cozma street, no.3, Iasi, 700554, Romania.

E-mail: daniela.ionescu27@yahoo.com

\section{Introduction}

Within the present study, we analyzed the contribution of several personality traits (neuroticism, optimism, motivational persistency, self authenticity, and selfconcordance in goal pursuit of the individual) in the progress made towards achieving goals and satisfying basic psychological needs. These traits can influence the orientation towards certain types of goals and the availability to make sustained efforts towards their accomplishment. Neuroticism and negative emotionality are a predisposition towards choosing goals centered on avoiding negative consequences and represent a factor which can sabotage the effective pursuit of important lifegoals. On the other hand, optimism and positive expectations concerning the achievement of one's goals support the individual from a motivational point of view and facilitate its capacity to make the necessary efforts and persist in the pursuit of his goals.

Factors dealing with the individual self and selfidentity, such as self-authenticity and self concordance in goal pursuit, play a fundamental role in the successful accomplishment of goals. Forming a self-identity, associated with the capacity of self-awareness, constitute a regulatory factor in the cognitive process, contributing to the generation and pursuit of goals which are concordant with the individual's authentic self, increasing thus the chances of success in achieving them and the satisfaction of basic psychological needs.

Conceptualizing the basic psychological needs from selfdetermination's theory perspective

From Goals are pursued to the extent in which the individual considers that fulfilling them shall contribute to satisfying his basic psychological needs (the need for competence, autonomy and relatedness). These represent a strong motivating factor for the commitment towards the goal. The theory of self-determination takes into consideration those needs which energize the goal-oriented behavior, offering content from a psychological point of view and allowing for the understanding of the goal-pursuit process. The scholarly literature concerning motivation often overlooks these basic needs, highlighting, in exchange, goals and behaviors.

White (1959) is the first to have conceptualized the basic psychological needs in almost full agreement with 
the current theory of self-determination. The need for competence could be generated by a form of individual energy, a tendency towards an effective organization of the environment towards achieving the best results. Autonomy involves the willingness dimension and refers to the desire of being independent in action and organizing one's life in agreement with its own authentic self (Sheldon and Elliot, 1999). The need for relatedness refers to the inborn desire of loving and being loved, of taking care of others and being taken care of (Baumesteir and Lary, 1995).

The satisfaction of these needs is essential to the process of individual growth and development, as it is significantly and positively associated with a psychological state of well-being. The need for autonomy has a central place among the three mentioned needs. Should the need for competence and relatedness be satisfied by acting on the basis of extrinsic motivation, the need for autonomy is essential in order to become a self-determined person and demands a motivated intrinsic behavior, in agreement with one's own individual self (Deci and Ryan, 2000).

Within the theory of self-determination, the needs for autonomy, competence and relatedness are conceptualized as being in-born needs, having a defining role for the individual's psychological well-being and his harmonious development. These needs are fundamental as the lack of satisfaction of one of the three leads to states of illness for the human body, both psychologically and physically. The fundamental character of these three needs is explained by the theory of self-determination due to the fact that individual is natively oriented towards growth and development, and towards the authentic integration on the self level and the larger social one. Thus, the individual has an inborn tendency to interact with others, to feel autonomous and to demonstrate that he is capable, all these aiming towards social integration and personal development. The satisfaction of these needs is an important predictor of mental health. People have an inborn tendency to pursue those goals which can facilitate the satisfaction of basic psychological needs.

The functional role of behavior can be considered that of reducing internal tension generated by the activation of psychological needs. One acts in order to satisfy a need. However, when these needs become automatic ones, one is not always aware of the motives behind their actions and does not attribute them with the meaning that could direct them towards satisfying certain needs. When one's needs are satisfied on an optimal level, one acts by virtue of creating prioritary interests meant to bring pleasure. A significant difference between physiological needs and psychological ones is that the threatening of the former ones leads towards an explicit behavior directed towards satisfying them, while the threatening of psychological needs can lead in time to a behavior of accommodation to the situation, less aware and with negative effects on the long-term psychological well-being. Individuals reach that point where they are no longer aware of their own needs, acting as a result of external reasons and becoming nonauthentic with themselves in their actions. In this case, one can refer to an entire process of personal self-sabotaging (Deci and Ryan, 2000).

\section{Personality traits}

Action orientation and emotional balance contribute to the progress in achieving important life goals, even if these are sometimes conflicting ones (Bordeaux and Ozer, 2013).

Motivational persistency engenders the maintenance of action on a certain path previously chosen in order to achieve a goal, dealing with the risks and difficulties which tend to manifest (Zhao, 2014).

Factors facilitating motivational persistency - Among those factors strengthening persistency one can find: effort compensation, social support, positive feedback, selfcontrol, the relevance of the task for the individual self. Psychological problems reduce the level of persistency. Persistency is a human capacity which can be improved through training.

Factors acting as a brake of motivational persistency Sometimes, people establish by themselves barriers on their way towards success, by adopting the selfhandicapping mechanism. Self-handicapping is operationalized as being the failure in persistency especially as far as major tasks are concerned. This mechanism serves for the protection or the increase of selfesteem through the alteration of those attributions which could be accomplished after success or failure. Should an individual not be persistent enough before taking a test and then fails, the reason for the failure remains ambiguous. Should the individual succeed, the reason shall be explained through his developed abilities. Thus, selfhandicaping protects one's self-esteem in the event of failure and increases the former in the event of success. People having a low self-esteem tend to adopt this mechanism (Peterson and Seligman, 2005).

Neuroticism is a major field of personality, involving lack of adaptation and negative emotionality. Neuroticism represents the tendency towards a rapid arousal in the presence of stimulation and inhibition slowness; the tendency to have unrealistic ideas; an incapacity to control negative events; a tendency towards lamenting; ineffective stress coping mechanisms; the tendency to evaluate events as being stressful; the tendency to experience aversive emotional states. The term of anxiety as a feature is often used as a synonym for neuroticism (Ormel et al., 2004).

Emotional instability associated with low planning capacity hardens the process of goal achievement. Emotional instability can be a precursor of goal conflict (MacLeod \& Conway, 2007). Neuroticism is an important factor in orienting towards avoidance goals. Neurotic individuals are sensitive to negative stimuli and predisposed to experiencing negative emotions such as anxiety and distress. Thus, their main focus is on the means to avoid situations which generate such emotions. Consequently, they tend to choose, to a large extent, goals focused on avoiding failure and negative consequences, an orientation which has a negative impact on progress in achieving important life goals and over their well-being. An individual having a high level of neuroticism tends to have low self-esteem, which directs him towards choosing goals oriented towards avoiding negative situations, in order to be able to protect his self-esteem (Heimpel et al., 2006).

As far as emotionally unstable individuals are concerned, resources are limited, as they do not have a good capacity of behavior self-regulation so as to maintain themselves focused on the intended goal. Goal-oriented behavior and the monitoring of progress are consumers of energetic resources and involve mental control and willingness power. Certain types of goals involve a large use of resources and energy and those goals focused on avoiding negative consequences are more likely part of this category. Monitoring progress in this type of goals represents only the absence of a negative state, and not the achievement of a certain accomplishment that would induce a positive state and would thus contribute to the 
consolidation of commitment towards the goal, which cal lead to the satisfaction of basic psychological needs and to psychological well-being (Elliot \& Sheldon, 1997). Neuroticism has a negative impact over goal-achievement. Neuroticism breaks the causal chain of success as far as goal achievement is concerned throughout the associated negative emotions. Neurotic individuals tend to be less satisfied with their lives and enjoy a reduced psychological well-being (Diaz et al., 2011).

Dispositional optimism refers to a person's tendency to be motivated by the belief according to which expected results are easily attainable. Optimism has beneficial effects on human physical and mental state (Kenedy et al., 2004). Carver and Scherier (1998) conceptualized optimism as a unidimensional construct (in the Life Orientation Test model), with optimism on one side and pessimism on the other. Other studies suggested a structure having two factors, which include two separate, but related-to dimensions: optimism and pessimism (Chang, D'Zurilla, Maydeu-Olivares, 1994).

Optimism has been associated with a higher progress in goal achievement, a low level of conflict in elaborating personal goals and with the attribution of a stronger significance to personal goals. Unlike pessimists, optimists make greater efforts in achieving their goals and when confronted with difficulties they have coping mechanisms which involve the reformulation of the goal and not its abandonment (Segerstorm et al., 2012).

Optimists use constructive coping mechanisms, active planning, the search of instrumental support, while the stressing factor is perceived as more easily controllable or positive reinterpretation, return to religion, humor and acceptance when the stressing factor is perceived as less controllable (Grote et al., 2007).

\section{The self and the pursuit of goals}

Previous Throughout his development, the individual forms his self-identity in the process of social interactions, and group and collective integration. Later on, he selects those social environments which are in agreement with his moral values and personal goals. The decision to maintain the connection with certain social environments is based not only on pragmatic motivations - social, belonging and relational interaction motivations (for instance, the motivation to obtain the recognition and social validation of the respective group), but also on the need for competence and autonomy (Ryan and Deci 2015).

Self-authenticity has an important impact in establishing and pursuing life goals. Achieving a high degree of authenticity engenders self-knowledge and contributes to a high level of concordance between the one's authentic self and one's actions and interactions (Scharff 2010).

An individual is authentic and autonomous when he has freedom of action and decision-making. The person who acts autonomously enjoys a greater feeling of concordance between the established goals and actions, chooses her type of behavior deliberately in various situations, manifests in agreement with her own beliefs, feelings and values, manifests greater tolerance to frustration, has a high degree of honesty in the interactions with the others, adapts flexibly to demands and develops her personal style (Kernis and Goldman 2006).

Mental comfort decreases significantly when the person attempts to deal in a conventional and rigid manner with various situations, when she makes intense efforts to answer demands stemming from principles she does not understand or accept completely.

Self-concordance in pursuing life goals is an important factor influencing the adoption of various regulatory mechanisms which lead towards goal fulfillment (Ryan, 1995). Self-concordant goals are those supported by an intrinsic motivation (Deci \& Ryan, 2008; Weinstein \& Ryan, 2011). When the pursued goal is in accordance with the individual self and valued by the subject, motivational persistency is increased. Goals established in an autonomous manner, supported by an intrinsic motivation are associated with making a greater effort and a larger progress towards achieving them (Bagøien, Halvari, \& Nesheim, 2010; Halvari et al., 2009; Hagger \& Chatzisarantis, 2007).

Intrinsic motivation mediates the relationship between self-concordant goals and the progress made towards achieving them. Should the goal be supported by an intrinsic motivation, the goal oriented behavior is easily adopted and the availability towards increased efforts grows. Thus, the goal has greater chances to be accomplished, and the progress made towards accomplishing it leads to satisfying basic needs, which has a positive impact on the psychological well-being (Downie et al., 2006).

The aim of this study is to explore the role of personality variables on the progress made in achieving goals and satisfying basic psychological needs (the need for autonomy, competence and relatedness).

\section{Method}

\section{Participants}

The participants in this study consisted of 231 subjects of the regular population, aged between 20 and 43 years old $(M=25,6 ; S D=7,33)$, all having completed higher education, of which 134 are women and 94 are men.

\section{Measures}

Sheldon and Elliot self-concordance scale (1999) participants are asked to note down their most important goal for the present time and the evaluation of reasons lying at the basis of goal pursuit with reference to 11 items. The Sheldon and Elliot scale of 4 items was extended to 11 items. For each descriptor of the items included in the original scales, a separate item was composed. The factorial analysis confirmed the conceptual structure of the initial scale $(\mathrm{KMO}=.635$; Bartlet Test of Sphericity: Chi Square $=409.58 ; d f=55 ; \mathrm{p}<.000)$. It results thus a structure of 4 factors which explains $72.20 \%$ of the variance. The scale has an acceptable internal consistency (alpha Cronbach coefficient is .65). For every item, the subject evaluates the following aspects as well: 1) the extent to which he pursues the goals out of his free will; 2) the extent in which he pursues the goals due to external reasons; 3 ) the past and present effort made in pursuing the goal; 4) past and present effort made in achieving the goal.

Life Orientation Test (Scheier et al., 1994) measures dispositional optimism, the individual's optimistic orientation, as opposed to the pessimistic one. It has a number of 14 items. The internal consistency coefficient alpha Cronbach for this scale is .75 .

Zuckerman - Kuhlman Personality Questionnaire neuroticism scale (Zuckerman et al., 1993) - the scale measures neuroticism as a pattern of negative emotionality 
and has 19 items. The internal consistency coefficient alpha Cronbach is .83 .

The Self Authenticity Scale (Wood et al., 2008) - the scale evaluates self authenticity, the extent in which the individual feels and acts in contact with his authentic self, and is aware of his own self. The scale has 12 items and the internal consistency coefficient alpha Cronbach of .82 .

Past and current effort and progress have been evaluated according to the methodology suggested by Sheldon and Elliot (1999), by grading the degree of involvement in achieving the intended goals and the progress made. For these scales the alpha Cronbach registered values between .70 and .74 . It evaluates the perception of the subject over the made effort and the achieved progress in various temporal stages (past and present).

The satisfaction of basic psychological needs scale (Sheldon el al., 1999) - it measures the satisfaction of the needs of autonomy, competence and relatedness, the extent to which the individual feels autonomous in actions and decisions, and the extent to which a person considers herself competent and in contact with the others. The scale has 9 items and the internal consistency coefficient alpha Cronbach is .79.

\section{Procedure}

The working instruments have been distributed to three groups of students of the Faculty of Psychology and Educational Sciences of the University of Bucharest. Their assignment was to fill in the questionnaires themselves and then apply them to two other adults over 30 years old, who have already completed higher education (at least BA degree). Each student received three sets of printed questionnaires which they filled in, along with two other persons, in a timeframe of two weeks.

The data analysis has been performed by resort to correlation and linear regression analyses.

\section{Results}

Table 1 presents the correlations between the study's variables. One can observe significant correlations between personality variables and the indicators of success in achieving goals (the registered progress and effort, the satisfaction of basic psychological needs). Selfconcordance in goal pursuit manifests a high association with present and past effort and progress in achieving these goals.

Table 2 presents the indicators of success in achieving goals and their determinant factors. The author used simultaneous linear regression analysis. The predictors of success factors in achieving goals, represented by current progress and the satisfaction of basic psychological needs, are to be found in Table 2 .

Table 2. Current progress in achieving goals and satisfying basic psychological needs - determinant factors

\begin{tabular}{lll}
\hline $\begin{array}{l}\text { Indicators of success } \\
\text { achieving goals }\end{array}$ & in & Determinant factors \\
\hline Current progress & Self-concordance in goal \\
& pursuit & \\
& Past effort & \\
& Present effort & \\
& Optimism & \\
& Self authenticity & \\
& Motivational persistency \\
\hline The satisfaction of $\quad$ basic & Self-concordance in goal \\
psychological needs & pursuit \\
& Current progress in achieving \\
& the goal \\
& Optimism \\
& Self authenticity \\
& Neuroticism \\
& Motivational persistency \\
\hline
\end{tabular}

Additionally, current progress represents a predictor for satisfying basic psychological needs. This relationship is also supported by the causal model of goal selfconcordance (Sheldon \& Elliot, 1999), in which current progress acts as a determinant factor of basic psychological needs, which lead to the individual's psychological wellbeing.

Results reveal the following positive predictors for current progress towards goal achievement (see Table 3): self-concordance in goal pursuit, motivational persistency, past and present effort in goal achievement, self authenticity and dispositional optimism. These explain together $73 \%$ of the variance in the criterion variable. Those individuals who pursue goals which are in concordance with their authentic self, that manifest motivational persistency and make a sustained effort throughout time in order to achieve their goals, relating optimistically to the future, have better chances to obtain a high progress in achieving their life goals.

The following predictive model highlights the predictive role of motivational and personality factors in satisfying basic psychological needs (see Table 4). The model comprises the following positive predictors: selfconcordance in goal pursuit, motivational persistency, selfauthenticity, and a negative predictor represented by neuroticism. These altogether explain $48 \%$ of the variance in the criterion variable. Those individuals who pursue goals in accordance with their individual self are authentic to themselves in what they do, have a low level of neuroticism, and satisfy to a large extent their needs for autonomy, competence and relatedness.

Table 1. Correlations between variables

\begin{tabular}{lllllllllllllllll}
\hline Variables & 1 & 2 & 3 & 4 & 5 & 6 & 7 & 8 & 9 & 10 & 11 & 12 & 13 & 14 & 15 \\
\hline 1. Present effort & - & & & & & & & & & & & & & \\
2. Past effort & $.79^{* *}$ & - & & & & & & & & & & & \\
3. Present progress & $.79^{* *}$ & $.68^{* *}$ & & & & & & & & & & \\
4. Past progress & $.62^{* *}$ & $.82^{* *}$ & $.83^{* *}$ & & & & & & & & & \\
5. Need for autonomy & .02 & .06 & $.24^{* *}$ & $.26^{* *}$ & & & & & & & & & \\
6. Need for competence & $.26^{*}$ & $.25^{* *}$ & $.46^{* *}$ & $.41^{* *}$ & $.47^{* *}$ & & & & & & & & \\
7. Need for relatedness & $.23^{* *}$ & $.19^{*}$ & $.39^{* *}$ & $.32^{* *}$ & $.35^{* *}$ & $.39^{* *}$ & & & & & & & & \\
\hline
\end{tabular}




\begin{tabular}{|c|c|c|c|c|c|c|c|c|c|c|c|c|c|c|c|}
\hline Variables & 1 & 2 & 3 & 4 & 5 & 6 & 7 & 8 & 9 & 10 & 11 & 12 & 13 & 14 & 15 \\
\hline $\begin{array}{l}\text { 8. Basic psychological } \\
\text { needs }\end{array}$ & $.22^{*}$ & $.24 * *$ & $.47^{* *}$ & $.43^{* *}$ & $.79^{* *}$ & $.80^{* *}$ & $.72^{* *}$ & - & & & & & & & \\
\hline $\begin{array}{l}\text { 9. Motivational } \\
\text { persistency }\end{array}$ & $.28^{* *}$ & $.25^{* *}$ & $.35^{* *}$ & $.32^{* *}$ & $.21 * *$ & $.49^{* *}$ & $.24 *$ & $.41^{* *}$ & - & & & & & & \\
\hline 10. Neuroticism & .03 & .08 & $-.23 * *$ & $-.21 * *$ & $-.49^{* *}$ & $-.38^{* *}$ & $-.31^{* *}$ & $-.51^{* *}$ & $-.15^{* *}$ & _ & & & & & \\
\hline 11. Optimism & $.17 *$ & $.14 *$ & $.37^{* *}$ & $.29^{* *}$ & $.49^{* *}$ & $.57^{* *}$ & $.49^{* *}$ & $.67^{* *}$ & $.34^{* *}$ & $-.54^{* *}$ & _- & & & & \\
\hline 12. Authenticity & .06 & .09 & $.22 *$ & $.15^{*}$ & $.57^{* *}$ & $.39^{* *}$ & $.20^{* *}$ & $.51^{* *}$ & .12 & $-.54^{* *}$ & $.42^{* *}$ & $\ldots$ & & & \\
\hline 13 Life satisfaction & $.13^{*}$ & & $.30^{* *}$ & $.25 * *$ & $.49^{* *}$ & $.55^{* *}$ & $.40^{* *}$ & $.62^{* *}$ & $.27^{*}$ & $-.38^{* *}$ & $.59^{* *}$ & $.32 * *$ & - & & \\
\hline $\begin{array}{l}\text { 14. Psychological well- } \\
\text { being }\end{array}$ & $.25^{* *}$ & $.25 * *$ & $.45^{* *}$ & $.41^{* *}$ & $.57^{* *}$ & $.63^{* *}$ & $.42^{* *}$ & $.70^{* *}$ & $.43^{* *}$ & $-.54^{* *}$ & $.65^{* *}$ & $.43^{* *}$ & $.54^{* *}$ & - & \\
\hline $\begin{array}{l}\text { 15. Goal self- } \\
\text { concordance }\end{array}$ & $.22 * *$ & $.17 *$ & $.26^{* *}$ & $.19 * *$ & $.17 * *$ & .11 & $.18^{* *}$ & $.19 * *$ & $.15^{*}$ & -.09 & $.22 * *$ & $.17 * *$ & .07 & $.21 * *$ & - \\
\hline
\end{tabular}

Notes: ${ }^{* *} p<.01,{ }^{*} p<.05$.

Table 3. Predictors of current progress in achieving goals

\begin{tabular}{llll}
\hline Predictors & $\boldsymbol{\beta}$ & $\boldsymbol{t}$ & Sig. $(\boldsymbol{p})$ \\
\hline Goal self-concordance & .19 & 4,287 & .000 \\
Motivational persistency & .07 & 1,962 & .05 \\
Past effort & .14 & 2,567 & .01 \\
Present effort & .49 & 7,576 & .000 \\
Self authenticity & .11 & 2,935 & .000 \\
Dispositional optimism & .14 & 3,504 & .001 \\
R square $=. \mathbf{7 3}$ & & & \\
\hline
\end{tabular}

Table 4. Predictors of the satisfaction of basic psychological needs

\begin{tabular}{llll}
\hline Predictors & $\beta$ & $\boldsymbol{t}$ & Sig. $(\boldsymbol{p})$ \\
\hline Goal self-concordance & .19 & 4.023 & .000 \\
Motivational persistency & .28 & 5,903 & .000 \\
Self authenticity & .29 & 5,484 & .000 \\
Neuroticism & -.31 & $-5,639$ & .000 \\
R square $=. \mathbf{4 8}$ & & & \\
\hline
\end{tabular}

\section{Discussion}

The Several motivational and personality factors are associated with success in achieving goals, success represented by the progress registered in achieving intended goals and satisfying basic psychological needs. The aim of our study was to explore the role of some personality and motivational variables in the process of pursuing important goals. We addressed factors that can sustain this process (goal self-concordance, selfauthenticity, motivational persistency, dispositional optimism) or factors that can sabotage the effective pursuit of one's goals (neuroticism). The progress made towards achieving a certain goal is a factor having a predictive role in the satisfaction of basic psychological needs. The relationship between current progress made towards achieving the goal and the satisfaction of basic psychological needs is supported also by studies dedicated to the self-concordance model (Sheldon \& Elliot, 1999), claiming that current progress in those goals that are concordant with the individual self is a predictor for the satisfaction of basic psychological needs, having a positive impact over the psychological well-being (Sheldon \& Elliot, 1999, Deci \& Ryan, 2008).

According to the self-concordance model (Sheldon and Elliot, 1999), effort and progress are determinant factors in the satisfaction of basic psychological needs. The current study introduces motivational persistency as a new explanatory factor for success in achieving goals. The role of motivational persistency in the process of goal pursuit is supported also by Constantin (2008). Motivational persistency engenders focusing on action towards achieving goals, facing those risks and difficulties which are likely to manifest (Zhao, 2014).

Those goals in accordance with the individual self, chosen in an autonomous manner, facilitate the necessary effort to progress and satisfy the needs for autonomy, competence and relatedness (Sheldon, 2002; Sheldon \& Elliot, 1999). Additionally, according to the present study, in order to achieve a higher progress in goal achievement, the individual needs to establish authentic goals, concordant with the individual self, to pursue perseveringly and optimistically, making constant efforts towards their satisfaction.

Self authenticity proved to be an important factor in satisfying basic psychological needs, fact which has been supported also by previous studies. Achieving an increased degree of authenticity engenders self-knowledge and the achievement of a feeling of concordance with the individual self in various actions and interactions (Scharff 2010), which leads to experiencing feelings of autonomy, competence and authentic interaction with others. The achieved results are in agreement with the selfconcordance model (Sheldon and Elliot, 1999), which stipulates the fact that those individuals pursuing goals that are concordant with the individual self achieve a higher progress in accomplishing them, which leads to the 
satisfaction of needs for autonomy, competence and relatedness (Scharff, 2010; Kernis and Goldman 2006).

The current study highlights the fact that a positively designed and balanced personality structure, or, otherwise put, a positive disposition and the absence of negative emotional states such as neuroticism, support an active involvement in life goals, the orientation towards opportunities and the registered success, facilitating the manifestation of feelings of autonomy, competence and authentic interaction. The present study introduces optimism and neuroticism as new explanatory concepts in the self-concordance model research field. Also, this study highlights the fact that optimism is an important success factor in goal achievement. Optimistic individuals tend to establish long term goals, concordant with the individual self, achieve a higher progress in accomplishing them and satisfy to a great extent their needs of autonomy, competence and relatedness. Positive expectations and optimism concerning the possibility of goal achievement support motivational persistency and lead the individual towards a goal-oriented behavior (Campbell and Warren, 2014). These results are in agreement with previous studies claiming that optimism is associated with a higher progress in goal achievement, a low level of conflict in elaborating personal goals and with the attribution of a powerful significance to personal goals (Anic et al., 2013).

The explanatory mechanism lying at the basis of the relationship between optimism and goal pursuit states that optimists tend to make a greater effort in achieving their goals and when they are confronted with difficulties, they present coping mechanisms which involve a reformulation of the goal and not its abandonment. The presence of optimism increases the chances for the individual to formulate goals that are concordant with the individual self, to persist in their accomplishment and to overcome the occurred difficulties, leading to an increase in their psychological well-being (Bodeaux et al., 2013). On the other hand, neuroticism engenders the experiencing of negative emotional states which sabotage the process of goal pursuit and the satisfaction of basic psychological needs. MacLeod and Conway (2007) claim that negative emotionality is associated with an incoherence of an individual's goals' system. Neurotic individuals are more likely to establish goals focused on avoiding negative consequences, as these tend to consume resources and personal energy. Monitoring progress in this type of goals represents only the absence of a negative state, and does not engender the achievement of a certain state that would induce a positive feeling and that would contribute to the satisfaction of basic psychological needs and increase the psychological well-being (Elliot \& Sheldon, 1997). Neurotic individuals are predisposed to experience an anticipatory anxiety connected to the pursued goal. Focusing on avoidance goals involves aversive psychological processes which lead to an increase in experienced stressful events and to the lack of satisfaction of one's basic psychological needs (Elliot et al., 2005). Neuroticism was associated with a low perception of autonomy, competence and relatedness (Judge et al., 2005).

Our life goals are elements having a structural role in our psychic life, but not any goal is healthy, with the exception of those goals which are concordant with one's individuality and one's authentic self. These goals have greater chances of being fulfilled, contributing to the satisfaction of the needs for autonomy, competence and relatedness, contributing thus to the good psychological functioning of the individual and its well-being.
Limits of the current study

A limit of the present study consists of the relatively small number of participants which does not allow for the testing of causal explanatory models in order to achieve a more accurate understanding of the manner in which motivational and personality factors contribute to the progress in goal achievement and the satisfaction of basic psychological needs. Additionally, sex distribution is not homogeneous throughout the sample.

Another limit is the lack of longitudinal factor analysis that could better explain success in the achievement of goals. For further studies, the author recommends the extension of the research methodology and considers longitudinal analyses appropriate to assess the factors that are associated with success in greater life goals achievement. These types of goals can be considered life goals which define the individual in multiple fields of his life. However, they might be more difficult to approach, since they are characterized by a high degree of generality and progress towards their accomplishment might be harder to achieve.

Additionally, further studies should focus on investigating other personality factors having an explanatory role in goal progress and the satisfaction of basic psychological needs, as well as other co-variant variables which can explain progress towards the goal and the satisfaction of needs for autonomy, competence and relatedness.

\section{References}

Anić, P., Tončić, M. (2013). Orientations to Happiness, Subjective Well-being and Life Goals. Psihologijske teme, $22,1,135-153$

Bagøien, T.E, Halvari, H., \& Nesheim, H. (2010). Selfdetermined motivation in physical education and its links to motivation for leisure-time physical activity and wellbeing in general. Perceptual and Motor Skills, 111, 407432.

Boudreaux, M., Ozer, D. (2013). Goal conflict, goal striving, and psychological well-being. Motiv Emot, 37:433-443

Baumeister, R. F. \& Leary, M. R. (1995). The need to belong: Desire for interpersonal attachments as a fundamental human motivation. Psychological Bulletin, 117, 497-529.

Carver, C. S., \& Scheier, M. F. (1998). On the self-regulation of behavior. New York: Cambridge University Press.

Campbell, M., Warren, C. (2014). The Progress Bias in Goal Pursuit: When One Step Forward Seems Larger than One Step Back. Journal of consumer research, Vol. 41.

Chang, E.C., D'Zurilla, T.J. \& Maydeu-Olivares, A. (1994). Assessing the dimensionality of optimism and pessimism using a multimeasure approach. Cognitive Therapy and Research, 18,2, 143-160.

Chang, E.C. (2002). Optimism-Pessimism and Stress Appraisal: Testing a Cognitive Interactive Model of Psychological Adjustment in Adults. Cognitive Therapy and Research, 26, 5, 675-690.

Díaz, R., Arroyo, J. (2011). Personality Factors, Affect, and Autonomy Support as Predictors of Life Satisfaction. Univ. Psychol., 12, 1.

Downie, M., Koestener, R., Horberg, E., Haga, S. (2006). Exploring the Relation of Independent and Interdependent Self-Construals to Why and How People Pursue Personal Goals. The Journal of Social Psychology, 146(5), $517-$ 531.

Deci, E. L., Ryan, R. M. (2000). The "what" and "why" of goal pursuits: Human needs and the self-determination of behavior. Psychological Inquiry, 11, 4, 227-268. 
Deci, E. L., \& Ryan, R. M. (2008). Hedonia, eudaimonia, and well-being: An introduction. Journal of Happiness Studies, 9, 1-11.

Elliot, A. J., \& Sheldon, K. M. (1997). Avoidance achievement motivation: A personal goals analysis Journal of Personality and Social Psychology, 73, 171185.

Elliot, A. J., Thrash, T. M., \& Murayama, K. (2011). A longitudinal analysis of self-regulation and well-being: Avoidance personal goals, avoidance coping, stress generation, and subjective wellbeing. Journal of Personality, 79, 643-674.

Grote, N., Bledoe, S., Larkin, J., Lemay, E., Brown, C. (2007) Stress Exposure and Depression in Disadvantaged Women: The Protective Effects of Optimism and Perceived Control. National Association of Social Workers.

Judge, T. A., Bono, J. E., Erez, A., \& Locke, E. A. (2005). Core selfevaluations and job and life satisfaction: The role of self-concordance and goal attainment. Journal of Applied Psychoiogy, 90, 257-268.

Heimpel, S., Elliot, A., Wood, J. (2006). Basic Personality Dispositions, Self-Esteem, and Personal Goals: An Approach-Avoidance Analysis. Journal of Personality, 74, 5.

Hagger, M.S., \& Chatzisarantis, N. (2007). The transcontextual model of motivation. In M.S. Hagger \& N. Chatzisarantis (Eds.), Intrinsic motivation and selfdetermination in exercise and sport (pp. 53-70). Champaign, IL: Human Kinetics.

Halvari, H., Ulstad, S.O., Bagøien, T.E., \& Skjesol, K. (2009). Autonomy support and its links to physical activity and competitive performance: Mediations through motivation, competence, action orientation and harmonious passion, and the moderator role of autonomy support by perceived competence. Scandinavian Journal of Educational Research, 53, 533-555.

Kernis, H. Michael, and Brian M., Goldman (2006). „A multicomponent conceptualization of authenticity: Theory and research. In Advances in Experimental Social Psychology, edited by Mark P. Zana, 38, 283 - 357. New York : Academic Press

Kennedy, Donna K; Hughes, Brian M. (2004). The optimismneuroticism question: an evaluation based on cardiovascular reactivity in female college students. The Psychological Record, 54, 3, 373-386.

Markus, H. R., \& Kitayama, S. (1991). Culture and the self: Implications for cognition, emotion, and motivation. Psychological Review, 98, 224-253.

MacLeod, A. K., \& Conway, C. (2007). Well-being and the anticipation of future positive experiences: The role of income, social networks and planning ability. Cognition and Emotion, 18, 357-374.
Ormel, J., Rosmalen, J., Farmer, A. (2004). Neuroticism: a non-informative marker of vulnerability to psychopathology. Soc Psychiatry Psychiatr Epidemiol, 39 : 906-912.

Peterson, C., Park, N., \& Seligman, M.E.P. (2005). Orientations to happiness and life satisfaction: The full life versus the empty life. Journal of Happiness Studies, 6, 2541.

Peterson, C. \& Seligman, M.E.P. (2004). Character strengths and virtues. A handbook and classification. Oxford University Press.

Ryan, M. R., Deci, E. L. (2015). Self-determination theory and the facilitation of intrinsic motivation, socia development, and well-being. American Psychologist, 55: 68-78.

Ryan, R. M. (1995). Psychological needs and the facilitation of integrative processes. Journal of Personality, 63, 397427.

Scharf, Miri, and Ofra, Mayseless. Finding the authentic self in a communal culture: Developmental goals in emerging adulthood. In The role of goals in navigating individual lives during emerging adulthood. New Directions for Child and Adolescent Development 130, edited by S Shulman \& J.-E. Nurmi, 83 - 95, 2010.

Sheldon, K. M., Sheldon, M. S., \& Osbaldiston, R. (1999). Prosocial values, assortation, and group selection in an $n-$ person prisoner's dilemma. Unpublished manuscript, University of Missouri,

Columbia, MO.

Sheldon, K. M., Kasser, T., Smith, K., \& Share, T. (2002). Personal goals and psychological growth: Testing an intervention to enhance goal attainment and personality integration. Journal of Personality, 70, 5-31.

Scharf, Miri, and Ofra, Mayseless (2010). Finding the authentic self in a communal culture: Developmental goals in emerging adulthood. In The role of goals in navigating individual lives during emerging adulthood. New Directions for Child and Adolescent Development 130, edited by S. Shulman \& J.-E. Nurmi, $83-95$.

Segerstrom, S., Stanton, A., Flynn, S., Roach, A., Testa, J., Hardy, J. (2012). Episodic repetitive thought: dimensions, correlates, and consequences. Anxiety, Stress, \& Coping, $25,1,3-21$.

Weinstein, N., \& Ryan, R.M. (2011). A self-determination theory approach to understanding stress incursion and responses. Stress and Health, 27(1), 4-17.

White, R. W. (1959). Motivation reconsidered: The concept of competence. Psychological Review, 66, 297-333.

Zhao, H., Wu, S. (2014). The power of motivation-goal fit in predicting entrepreneurial persistence. Social behavior and personality, 42(8), 1345-1352. 